\title{
How does an integrated primary care approach for patients in deprived neighbourhoods impact utilization patterns? An explorative study
}

Dionne S. Kringos ${ }^{1 *}$, Jennifer R. van den Broeke ${ }^{1}$, Arnold P. M. van der Lee ${ }^{2}$, Thomas Plochg ${ }^{1}$ and Karien Stronks ${ }^{1}$

\begin{abstract}
Background: To explore changes in utilization patterns for general practice (GP) and hospital care of people living in deprived neighbourhoods when primary care providers work in a more coherent and coordinated manner by applying an integrated approach.

Methods: We compared expected (based on consumption patterns of a health insurers' total population) and actual utilization patterns in a deprived Dutch intervention district in the city of Utrecht (Overvecht) with control districts 1 (Noordwest) and 2 (Kanaleneiland) over the period 2006-2011, when an integrated care approach was increasingly provided in the intervention district. Standardized insurance claims data were used to indicate use of GP care and hospital care.

Results: Our findings revealed that the utilization of total GP care increased more in the intervention district than in the control districts. And that the intervention district showed a more pronounced decreasing trend in total hospital use as compared to what was expected, in particular from 2008 onwards. In addition, we observed a change in type of GP care use in the intervention district in particular: the number of regular consultations, long consultations, GP home visits and evening, night and weekend consultations were increasingly higher than expected. The intervention district also showed the largest decrease between actual and expected use of ambulatory care, clinical care and 1-day hospitalizations.

Conclusions: Utilization patterns for general practice and hospital care of people living in deprived districts may change when primary care professionals work in a more coherent and coordinated manner by applying a more 'comprehensive' integrated care approach. Results support the expectation that a comprehensive integrated care approach might eventually contribute to the future sustainability of healthcare systems.
\end{abstract}

Keywords: Integrated delivery of health care, General practice, Use of GP care, Use of hospital care

\section{Background}

People living in deprived neighbourhoods have higher morbidity and mortality rates $[1,2]$, and they become chronically ill twice as often compared to more advantaged populations [3]. They not only suffer from multimorbidity 10 to 15 years earlier in their course of life [4], they also experience relatively more complexities in

\footnotetext{
* Correspondence: d.s.kringos@amc.uva.nl

'Department of Public Health, Academic Medical Center (AMC), University of Amsterdam, PO-box 22660, Amsterdam 1100 DD, The Netherlands

Full list of author information is available at the end of the article
}

other parts of their lives such as work, living conditions, income and upbringing [5].

The available evidence suggests that people in lower socioeconomic groups compared to higher groups receive more inappropriate care as regards their (often multiple) health and social care needs [6-9]. This mismatch results in unnecessary high health care consumption rates. Health care systems are not yet sufficiently geared towards treating patients with multiple health and social needs. Health care and social care services are fragmented and the provision of public health services is 
hardly structurally embedded in regular care [6]. In addition, many public health measures and health care approaches of professionals do not seem to fit the accumulation of health and social problems presented by patients (incl. e.g. their cultural diversity) from deprived neighbourhoods in their practice [7]. As a result, health problems remain unresolved leading to a high amount of frequent attenders in primary care [9], high referral rates from primary to specialized care, and inappropriate medication use [10-12].

The provision of integrated care is considered an important strategy for improving the quality of health care services delivery for patients with multiple care needs and reducing health care expenditures [10]. Integrated patient care implies an ability of health care professionals to "coordinate care across professionals, facilities, and support systems; continuous over time and between visits; tailored to the patients' needs and preferences; and based on shared responsibility between patient and caregivers for optimizing health" [13]. Integrated care approaches emphasize particularly the re-organization of processes, structures and systems to enable better coordinated care geared to the need of patients [14]. This requires a close collaboration between public health, primary care and social care [6, 15-17].

Although there are examples of implemented integrated care arrangements, the evidence base on the effectiveness of integrated care remains inconclusive thus far $[16,18-20]$. Amongst others, one reason is that integrated care arrangements focus on the optimizing of working processes and structures in the first place, and pay less attention to the health and social care professionals' expertise and attitude. This additional focus is important, as the success of integrating hinges not only on organizational structures, but also on the individuals' expertise and attitude to help patients with multimorbidity living in deprived circumstances [4, 21-24].

This theory was put into practice recently in a deprived district in The Netherlands, called Overvecht. An intervention was implemented with the aim to stimulate primary care professionals to improve their expertise, attitude, behaviour and tools to better support them to provide more comprehensive forms of integrated care. Within this area-based programme improvement of integrated care approaches led to professionals taking on a population health orientation, a focus on prevention, applying a generalist view to patients enabling the undertaking of cross domain actions, and coaching behaviour to empower patients to become participants in their own care processes and self-manage their own health [25].

Despite the high expectations of integrated care, it is currently unknown what health care utilisation patterns emerge when care is organised in a more coherent and coordinated fashion provided by competent professionals. Available research in this area is often limited to specific conditions and performed at individual patient level. Projects that have implemented such an integrated approach in a specific neighbourhood can be approached as natural experiments to study the way health care patterns evolve. Insight in appropriate health care utilization patterns of patients will support health services capacity planning, resource allocation, and will inform decision makers' considerations when contemplating scaling up integrated care transformations.

This study therefore aims to contribute to the evidence base by exploring the primary care and secondary care utilization patterns of residents of a deprived district in The Netherlands (Overvecht) where health and social care professionals in the period 2006-2011 increasingly have renewed their expertise, attitude, behaviour and tools to provide more tailored integrated services for their citizens, as part of an area-based programme [25]. In addition, we will compare these patterns with those in two control districts.

The area-based programme was initiated by a major Dutch health insurer (Agis Health Insurance) and the municipality of Utrecht in 2006. The background of this endeavour was rooted in the high health care consumption rates, the extreme bad self-perceived health status of residents, the high morbidity, and high unemployment rate. More than $50 \%$ of residents had at least one chronic disease, around half of residents had an increased risk of depression or anxiety disorder. In addition, one in five residents of the dictrict Overvecht were obese, half of residents were overweight, and one in three residents were socially isolated. Van den Broeke et al. (2015) [25] described the area-based programme aimed at promoting integrated care that health insurer 'Agis Health Insurance' with the Municipality of Utrecht implemented in the district Overvecht. Additional file 1: Table S1 summarizes the activities within the programme.

The implemented activities targeted three problems: the difficulty for professionals grasping the complexity of problems presented by patients in their practices, the difficulty with activating clients to self-manage their own health, and the fragmentation in health care provision. The interwoven problems were tackled with a more comprehensive solution consisting of 'generalism', 'coaching' and 'population health orientation'. All primary health care professionals working in the pilot district learned how to consider patients in their social contexts (taking a more holistic view) and understand what different problems a patient might have and how these might interact. The professionals became more able to coach patients to actively take part in solving their health and social problems. They gradually succeeded in developing 
this comprehensive integrated care approach together and spread it throughout the district which is still an ongoing process [25].

\section{Methods}

\section{Study period}

The study period ranges from 2006 to 2011, the period in which the pilot interventions were implemented (Additional file 1: Table S1). A previous study has shown that during the intervention period, primary care professionals in the intervention district increasingly accustomed to a more integrated working approach over this period of time [25]. We therefore expect the impact of the integrated care approach on health care use to become increasingly stronger over the course of time.

\section{Study design and study population Intervention district}

The intervention district was Overvecht, a deprived district in Utrecht, The Netherlands. About $2 / 3$ of all residents in Overvecht is insured at 'Agis Health Insurance Company', which is the main health insurance company in the central part of the Netherlands, where Utrecht is located. For those inhabitants who were insured with Agis, we derived health care utilization data from the Agis Health Database (AHD) [26]. This database includes information on payments for the provision of all medical care to its insured patients, along with demographic data of insured patients. The AHD has been shown to be representative for the urbanized areas of the Netherlands [26]. We selected data from the AHD for the whole intervention period (2006-2011).

Table 1 provides an overview of key characteristics of the intervention district. In 2006, the total number of residents in the intervention district that were insured at Agis Health Insurance was almost 20,000. Over the whole study period, 829 additional residents obtained health insurance at Agis Health Insurance.

\section{Control districts}

We compared the trends in health care use in the intervention district with the trend in two control districts in the city of Utrecht which were not part of the pilot study. These districts were similar in terms of national health policy, deprivation, percentage of the population insured with Agis Health Insurance, health insurers policy and professional standards of health care providers. Furthermore, no substantial changes occurred during the study period in the delivery of primary care in these districts. These control districts were 'Utrecht Noordwest', which we will call 'control district 1' (covering the areas 'Ondiep' and 'Zuilen-Oost'), and 'Kanaleneiland', which we will call 'control district 2'.
In 2006, the total number of residents insured at Agis Health Insurance was approximately 20,000 in control district 1 and 11,000 in control district 2 (Table 1). In control district 1 this number decreased over the study period with approximately $10 \%$. In control district 2 no substantial changes occurred.

The sociodemographic composition of the population in the control districts differed in some aspects from that in the intervention district, e.g. with regard to age. For that reason, in the statistical analyses, we controlled for a number of potential confounders at the level of both the individual residents and the district (see section on statistical analyses).

\section{Measures}

\section{Health care use}

Although the intervention aimed at realizing a change in the attitude, behaviour and working approaches of primary care workers in particular [25], one would expect this also to have consequences for health care consumption at hospital level, e.g. due to changing referral behaviour of general practitioners. For that reason, we included both utilization of general practice care and hospital care, as registered in the AHD, as an outcome measure.

With regard to consumption of GP care, we made a distinction between different types of care. To compute an overall consumption profile we used weighting factors that take into account the content, duration and costs of the services, as developed by the Dutch Healthcare Authority [27]. The types (and corresponding weights) are: regular consultations (1), telephone consultations (0.5), long consultations (2), evening/night or weekend consultations (2), and home visits (2).

With regard to hospital services, the AHD allows for a distinction between ambulatory care, clinical care and 1day hospitalisation. Diagnostic/treatment codes are used for the reimbursement of hospital services. To compute an overall consumption profile for each of these hospital services, we used weight as developed by Agis Health Insurance, again taking into account the content, duration and costs of the services. The total hospital care utilization profile thus included the number (with corresponding weight) of ambulatory diagnosis/treatment codes (1), clinical diagnosis/treatment codes (10), and 1day hospitalizations diagnosis/treatment codes (4).

\section{Confounders}

Several covariates were used to control for potential confounding: age (5 years categories), gender, and comorbidity (based on payments as registered in AHD for the provision of medical care in relation to a number of specified chronic conditions) at the individual level; and socioeconomic status at the level of the district (based 
Table 1 Key characteristics in 2006 and 2011 of the intervention district and two control districts in comparison to the whole of Utrecht City

\begin{tabular}{|c|c|c|c|c|}
\hline Socio-demographics: & $\begin{array}{l}\text { Overvecht } \\
\text { intervention district }\end{array}$ & $\begin{array}{l}\text { Utrecht Noordwest (only Ondiep/ } \\
\text { Zuilen-Oost) control district } 1\end{array}$ & $\begin{array}{l}\text { Kanaleneiland } \\
\text { Control district } 2 \\
\end{array}$ & $\begin{array}{l}\text { Utrecht City } \\
\text { (total) }\end{array}$ \\
\hline \multirow[t]{2}{*}{ Total population } & 2006: 31,403 & 2006: 40,613 & 2006: 15,270 & $\begin{array}{l}2006: \\
281,011\end{array}$ \\
\hline & 2011: 31,422 & 2011: 40,862 & 2011: 15,593 & $\begin{array}{l}\text { 2011: } \\
311,405\end{array}$ \\
\hline \multirow[t]{2}{*}{$\% 65$ years or older } & 2006: $17.3 \%$ & 2006: $11.5 \%$ & 2006: $9.5 \%$ & $\begin{array}{l}2006: \\
10.6 \%\end{array}$ \\
\hline & 2011: $16.0 \%$ & 2011: $10.9 \%$ & 2011: $8.7 \%$ & 2011: $9.8 \%$ \\
\hline \multirow[t]{2}{*}{ Non-western immigrants } & 2006: $40.4 \%$ & 2006: $25.4 \%$ & 2006: $70.5 \%$ & $\begin{array}{l}2006: \\
20.8 \%\end{array}$ \\
\hline & $2011: 45.6 \%$ & 2011: $25.9 \%$ & 2011: $70.1 \%$ & $\begin{array}{l}\text { 2011: } \\
21.5 \%\end{array}$ \\
\hline \multirow[t]{2}{*}{ Recipients of social benefits } & 2006: $24.8 \%$ & 2006: $20.3 \%$ & 2006: $23.6 \%$ & $\begin{array}{l}2006: \\
14.3 \%\end{array}$ \\
\hline & 2011: $22.7 \%$ & 2011: $15.9 \%$ & 2011: $19.9 \%$ & $\begin{array}{l}2011: \\
11.6 \%\end{array}$ \\
\hline \multirow{2}{*}{$\begin{array}{l}\text { Insufficient income to manage daily living activities } \\
\text { (self-reported) }\end{array}$} & 2006: $10.5 \%$ & Not available & 2006: $17.5 \%$ & 2006: $6.2 \%$ \\
\hline & 2011: $12.8 \%$ & & 2011: $16.2 \%$ & $2011: 6.5 \%$ \\
\hline \multirow[t]{2}{*}{ Medium or bad health status } & 2006: - & Not available & 2006: - & 2006: - \\
\hline & $2011: 25.4 \%$ & & $2011: 26.6 \%$ & $\begin{array}{l}2011: \\
13.9 \%\end{array}$ \\
\hline \multicolumn{5}{|l|}{ Health care facilities: } \\
\hline \multirow[t]{2}{*}{ General practitioners per 10,000 residents } & 2006: 6.7 & 2006: 3.8 & 2006: 4.6 & 2006: 7.7 \\
\hline & 2011: 5.7 & 2011: 5.9 & 2011: 2.8 & 2011: 6.4 \\
\hline \multirow[t]{2}{*}{ Number of multidisciplinary health care centers } & 2006: Not available & 2006: Not available & 2006: Not available & \multirow{2}{*}{$\begin{array}{l}\text { Not } \\
\text { available }\end{array}$} \\
\hline & 2011: 5 & 2011: 1 & 2011: 2 & \\
\hline \multicolumn{5}{|l|}{ Distance to nearest hospital } \\
\hline - Diakonessenhuis & $-7.0 \mathrm{~km}$ & $-5,1 \mathrm{~km}$ & $-4,2 \mathrm{~km}$ & $\begin{array}{l}\text { Not } \\
\text { available }\end{array}$ \\
\hline \multicolumn{5}{|l|}{ Health Insurance } \\
\hline \multirow{2}{*}{$\begin{array}{l}\text { Number of residents with a health insurance at } \\
\text { Agis Zorgverzekeringen by year }\end{array}$} & 2006: 19,291 & Total in Utrecht Noordwest: & 2006: 11,241 & \multirow{2}{*}{$\begin{array}{l}\text { Not } \\
\text { available }\end{array}$} \\
\hline & 2011: 20,120 & 2006: 19,444 2011: 17,833 & 2011: 11,025 & \\
\hline
\end{tabular}

Source: $[38,39]$

on average disposable income, percentage social benefit recipients, percentage of residents from non-western origin, and number of residents per square kilometre).

\section{Statistical analyses}

We assessed the trend in health care use during the intervention period (2006-2011) in the intervention district, and compared this with the corresponding trend in the control districts. Results are presented as the number of consultations for a specific service per 1000 insured residents per year. In view of the exploratory aim of the analysis, we did not test for statistical significance.

As some sociodemographic attributes differ between the intervention and control districts as well as over time (Table 1), we could not simply rely on the data on actual use of health care. To account for the sociodemographic differences, we calculated the expected use of care, controlling for the aforementioned confounders (age, sex, socioeconomic status and comorbidity) using logistic regression analysis. The total population of Agis was used as the reference group and the correction was carried out per year. In this way the changes over time in national health care policy and the policy of the health care insurer Agis are accounted for. The result is that for every person in the study population expected values based on the consumption of all Agis insures are calculated.

We will present the average number of consultations per 1000 insured residents and compare these with the number of expected consultations, for both the intervention district and control districts. In order to assess the trend over time, we will present the change in actual versus expected number of consultations using the year 2006 as index. 


\section{Results}

Trends in total general practice care utilization and total hospital care utilization

Table 2 shows the actual and expected average health care use per 1000 insured clients, regarding total GP care and total hospital care. Residents in the intervention district are using more GP care than expected from 2007 onwards. Also in both control districts, during the whole study period, the use of GP care was higher than expected. In control district 2 the number of actual versus expected total GP care decreased over time. If we relate the use of care from 2007 onwards to the index year 2006, it becomes clear that the total GP care increased more in the intervention district than in the control districts, particularly compared to control district 2 (Fig. 1).

In the intervention district, from 2008 onwards, there has been a decrease in total hospital care use in relation to the number expected (Table 2). Although in some years, control district 1 shows a decrease in total hospital care use, we did not observe a systematic trend. As a result, the decreasing trend in total hospital use as compared to what was expected, was more pronounced in the intervention district, in particular from 2008 onwards (Fig. 1).

\section{Trend in general practice use by consultation type}

The divergent trends in total GP care between the intervention district and the control districts appears to conceal different patterns for different types of GP use (Table 3). Regarding regular GP consultations, only residents in the intervention district had less consultations than expected (Table 3). The usage increased since 2007 but remained lower than expected during the study period. Compared to the control districts, the intervention district showed a higher increase in actual use versus expected use with regard to regular and long consultations, GP home visits and evening, night and weekend consultations. This was particularly so in comparison with district 2 . As a result, for these types of GP care, we found divergent trends in the difference between actual and expected for the intervention district and control districts (Fig. 2). There were no noticeable differences between districts regarding telephone consultation (Table 3).

\section{Trends in hospital care utilization by type of service}

All districts show an increase in ambulatory care from 2009 and onwards, but this remains clearly lower than expected in the intervention district, in all years (Table 4). In control district 1 ambulatory care use is only above the expected level in 2011, while in control district 2 it is well above the expected level during the whole study period. As a result, the difference between the actual and expected levels of the intervention district and the two districts increased over time (Fig. 3). Looking at clinical care, all districts show a reduction in the difference between actual and expected average use, though the numbers are small and do not seem to differ much across districts (Table 4). While the differences with the control districts are small, the intervention district shows the largest negative difference between actual and expected use of clinical care from 2009 and onwards. The number of 1-day hospitalizations of residents in all districts is above expectation, with small

Table 2 Actual and expected use of total GP care and hospital care, in intervention district and control districts, 2006-2011

\begin{tabular}{|c|c|c|c|c|c|c|c|c|c|}
\hline \multirow[t]{2}{*}{ Year } & \multicolumn{3}{|c|}{ Intervention district } & \multicolumn{3}{|c|}{ Control district 1} & \multicolumn{3}{|c|}{ Control district 2} \\
\hline & $\begin{array}{l}\text { Number } \\
\text { actual per } \\
1000\end{array}$ & $\begin{array}{l}\text { Number } \\
\text { expected per } \\
1000\end{array}$ & $\begin{array}{l}\text { Difference } \\
\text { actual and } \\
\text { expected }\end{array}$ & $\begin{array}{l}\text { Number } \\
\text { actual per } \\
1000\end{array}$ & $\begin{array}{l}\text { Number } \\
\text { expected per } \\
1000\end{array}$ & $\begin{array}{l}\text { Difference } \\
\text { actual and } \\
\text { expected }\end{array}$ & $\begin{array}{l}\text { Number } \\
\text { actual per } \\
1000\end{array}$ & $\begin{array}{l}\text { Number } \\
\text { expected per } \\
1000\end{array}$ & $\begin{array}{l}\text { Difference } \\
\text { actual and } \\
\text { expected }\end{array}$ \\
\hline \multicolumn{10}{|c|}{ average weighted number of GP care units } \\
\hline 2006 & 4.122 & 4.279 & -157 & 4.135 & 4.128 & 7 & 4.468 & 4.032 & 436 \\
\hline 2007 & 4.532 & 4.510 & 22 & 4.380 & 4.326 & 55 & 4.604 & 4.243 & 361 \\
\hline 2008 & 4.763 & 4.605 & 157 & 4.701 & 4.469 & 232 & 4.849 & 4.384 & 465 \\
\hline 2009 & 5.119 & 4.876 & 243 & 4.862 & 4.751 & 112 & 4.944 & 4.655 & 289 \\
\hline 2010 & 5.053 & 4.973 & 80 & 4.974 & 4.878 & 96 & 4.946 & 4.743 & 204 \\
\hline 2011 & 5.257 & 5.191 & 66 & 5.244 & 5.088 & 156 & 4.996 & 4.964 & 32 \\
\hline \multicolumn{10}{|c|}{ average weighted number of hospital care units } \\
\hline 2006 & 2.689 & 2.538 & 151 & 2.612 & 2.518 & 94 & 2.556 & 2.350 & 206 \\
\hline 2007 & 2.668 & 2.567 & 100 & 2.637 & 2.581 & 56 & 2.598 & 2.437 & 160 \\
\hline 2008 & 2.538 & 2.578 & -40 & 2.609 & 2.582 & 26 & 2.488 & 2.441 & 48 \\
\hline 2009 & 2.735 & 2.829 & -94 & 2.864 & 2.918 & -55 & 2.766 & 2.712 & 55 \\
\hline 2010 & 2.858 & 2.994 & -136 & 3.109 & 3.077 & 31 & 2.851 & 2.812 & 39 \\
\hline 2011 & 2.947 & 3.085 & -138 & 3.163 & 3.182 & -19 & 2.982 & 2.960 & 21 \\
\hline
\end{tabular}




\section{Difference in actual versus expected weighted number of GP care units (2006=index)}

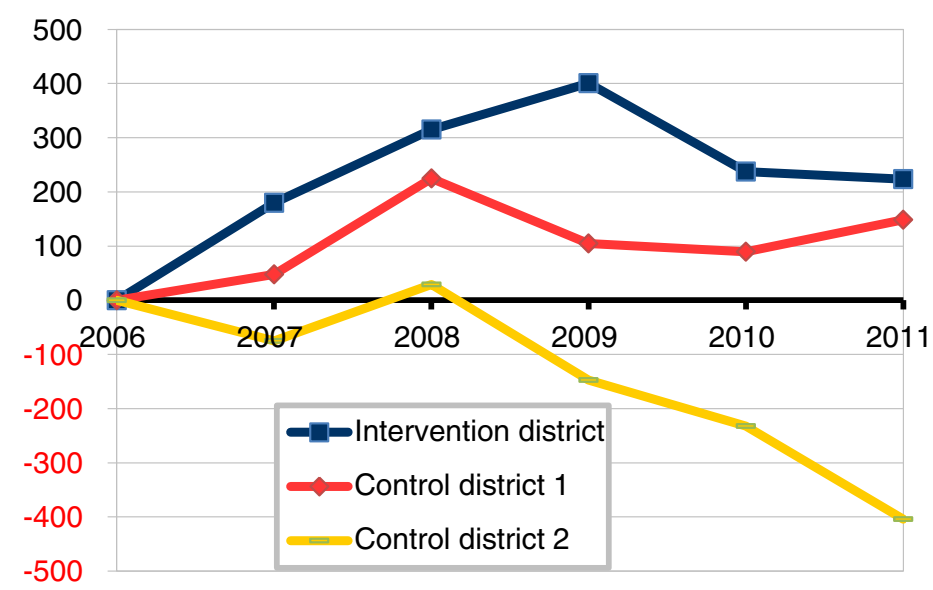

\section{Difference in actual versus expected weighted number of hospital care units (2006=index)}

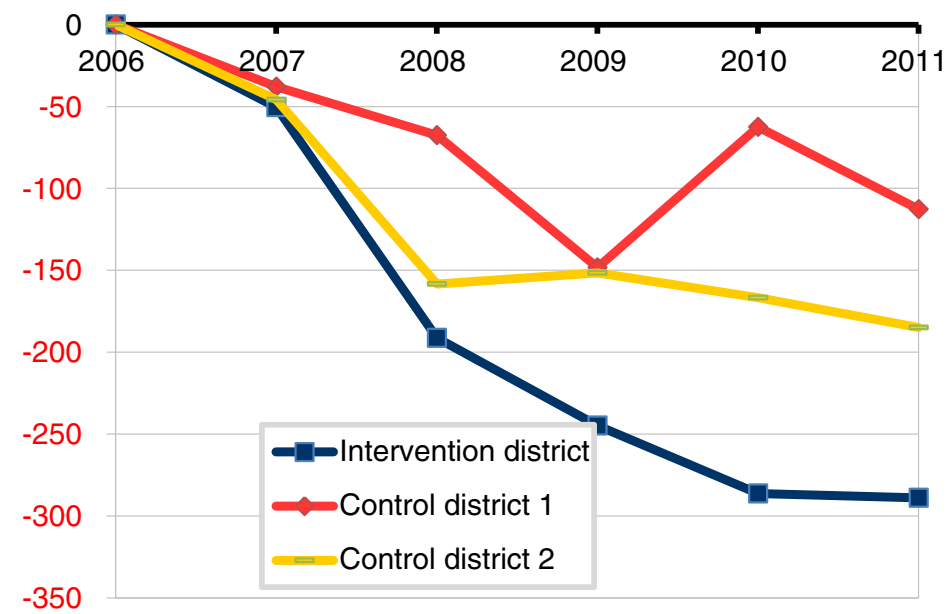

Fig. 1 Trend in actual versus expected weighted number units, for total GP care and total hospital care, 2006-2011 (index:2006), in intervention district and control districts. a. Difference in actual versus expected weighted number of GP care units (2006=index). $\mathbf{b}$ Difference in actual versus expected weighted number of hospital care units (2006 = index)

differences between districts. The intervention district shows the largest decrease between actual and expected use of 1-day hospitalizations.

\section{Discussion}

\section{Main findings}

Our study found changes in utilization patterns for general practice and hospital care of people living in deprived districts when primary care professionals work in a more coherent and coordinated manner by applying a comprehensive integrated care approach. We compared utilization patterns in the intervention district with those in two control districts over the period 2006-2011, while an integrated care approach was increasingly provided in the intervention district.

Our findings revealed that the utilization of total GP care increased more in the intervention district than in the control districts. And that the intervention district showed a more pronounced decreasing trend in total hospital use as compared to what was expected, in particular from 2008 onwards. In addition, we observed a change in type of GP care use in the intervention district in particular: the number of regular consultations, long consultations, GP home visits and evening, night and weekend consultations were increasingly higher than expected. The intervention district also showed the largest decrease 
Table 3 Actual and expected use of different types of GP care, in intervention district and control districts, 2006-2011

\begin{tabular}{|c|c|c|c|c|c|c|c|c|c|}
\hline \multirow[t]{2}{*}{ Year } & \multicolumn{3}{|c|}{ Intervention district } & \multicolumn{3}{|c|}{ Control district 1} & \multicolumn{3}{|c|}{ Control district 2} \\
\hline & $\begin{array}{l}\text { Number } \\
\text { actual per } \\
1000\end{array}$ & $\begin{array}{l}\text { Number } \\
\text { expected per } \\
1000\end{array}$ & $\begin{array}{l}\text { Difference } \\
\text { actual and } \\
\text { expected }\end{array}$ & $\begin{array}{l}\text { Number } \\
\text { actual per } \\
1000\end{array}$ & $\begin{array}{l}\text { Number } \\
\text { expected per } \\
1000\end{array}$ & $\begin{array}{l}\text { Difference } \\
\text { actual and } \\
\text { expected }\end{array}$ & $\begin{array}{l}\text { Number } \\
\text { actual per } \\
1000\end{array}$ & $\begin{array}{l}\text { Number } \\
\text { expected per } \\
1000\end{array}$ & $\begin{array}{l}\text { Difference } \\
\text { actual and } \\
\text { expected }\end{array}$ \\
\hline \multicolumn{10}{|c|}{ Regular GP consultations } \\
\hline 2006 & 2.323 & 2.584 & -262 & 2.566 & 2.511 & 55 & 2.744 & 2.465 & 279 \\
\hline 2007 & 2.448 & 2.600 & -151 & 2.651 & 2.522 & 129 & 2.698 & 2.476 & 222 \\
\hline 2008 & 2.497 & 2.630 & -133 & 2.745 & 2.554 & 192 & 2.775 & 2.515 & 260 \\
\hline 2009 & 2.556 & 2.700 & -144 & 2.733 & 2.619 & 114 & 2.799 & 2.586 & 213 \\
\hline 2010 & 2.477 & 2.620 & -144 & 2.667 & 2.557 & 110 & 2.766 & 2.510 & 256 \\
\hline 2011 & 2.530 & 2.656 & -126 & 2.711 & 2.609 & 103 & 2.707 & 2.550 & 156 \\
\hline \multicolumn{10}{|c|}{ Long GP consultations } \\
\hline 2006 & 246 & 237 & 9 & 194 & 234 & -40 & 252 & 218 & 34 \\
\hline 2007 & 363 & 330 & 33 & 267 & 317 & -50 & 365 & 302 & 63 \\
\hline 2008 & 450 & 367 & 82 & 335 & 360 & -26 & 452 & 341 & 111 \\
\hline 2009 & 503 & 425 & 78 & 369 & 416 & -47 & 418 & 395 & 23 \\
\hline 2010 & 521 & 495 & 27 & 409 & 477 & -69 & 409 & 458 & -49 \\
\hline 2011 & 575 & 565 & 10 & 503 & 541 & -38 & 447 & 524 & -77 \\
\hline \multicolumn{10}{|c|}{ Evening, night and weekend GP consultations } \\
\hline 2006 & 273 & 247 & 27 & 261 & 239 & 22 & 253 & 247 & 6 \\
\hline 2007 & 297 & 258 & 40 & 266 & 247 & 20 & 257 & 257 & 1 \\
\hline 2008 & 278 & 247 & 32 & 261 & 242 & 19 & 248 & 251 & -3 \\
\hline 2009 & 325 & 269 & 56 & 295 & 264 & 31 & 262 & 273 & -11 \\
\hline 2010 & 292 & 256 & 36 & 284 & 253 & 31 & 250 & 257 & -7 \\
\hline 2011 & 309 & 268 & 41 & 292 & 264 & 29 & 259 & 269 & -10 \\
\hline \multicolumn{10}{|c|}{ Telephone GP consultations } \\
\hline 2006 & 825 & 642 & 183 & 696 & 648 & 48 & 789 & 602 & 187 \\
\hline 2007 & 874 & 716 & 158 & 723 & 715 & 8 & 771 & 670 & 101 \\
\hline 2008 & 945 & 786 & 159 & 854 & 796 & 58 & 854 & 748 & 106 \\
\hline 2009 & 1.070 & 881 & 189 & 968 & 912 & 56 & 989 & 849 & 140 \\
\hline 2010 & 1.252 & 1.086 & 166 & 1.217 & 1.141 & 77 & 1.194 & 1.046 & 148 \\
\hline 2011 & 1.296 & 1.131 & 165 & 1.300 & 1.175 & 125 & 1.247 & 1.092 & 155 \\
\hline \multicolumn{10}{|c|}{ Home GP visits } \\
\hline 2006 & 175 & 204 & -29 & 155 & 173 & -18 & 160 & 168 & -8 \\
\hline 2007 & 163 & 189 & -25 & 151 & 160 & -9 & 138 & 157 & -19 \\
\hline 2008 & 169 & 177 & -8 & 169 & 157 & 12 & 125 & 156 & -32 \\
\hline 2009 & 186 & 173 & 12 & 159 & 159 & 0 & 145 & 154 & -9 \\
\hline 2010 & 162 & 154 & 8 & 157 & 145 & 12 & 133 & 140 & -7 \\
\hline 2011 & 155 & 152 & 4 & 146 & 141 & 4 & 126 & 141 & -15 \\
\hline
\end{tabular}

between actual and expected use of ambulatory care, clinical care and 1-day hospitalizations.

\section{Explanation of results}

The observed changes in the utilisation patterns in the intervention district are timely and relevant. Overvecht mirrors the initial dynamics within Dutch primary care featuring the development of more comprehensive integrated care arrangements to include professional competencies and attitudes as well [21, 25, 27]. The intervention has drawn much attention in The Netherlands [28], and its underlying principles are reinforced by the white paper of a national advisory committee on innovating healthcare professions 


\section{Difference in actual versus expected number of regular GP consultations $(2006=$ index $)$}

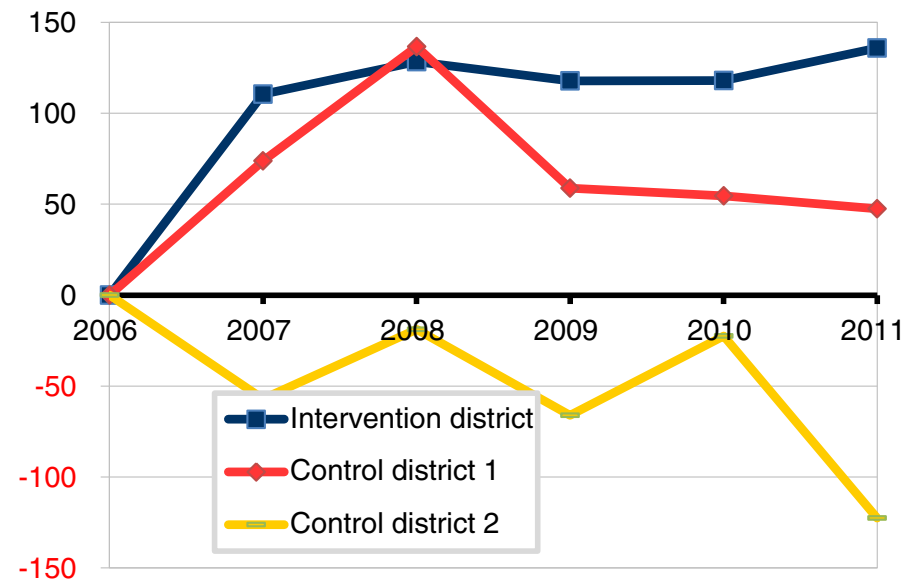

\section{Difference in actual versus expected number of long GP consultations $(2006=$ index $)$}

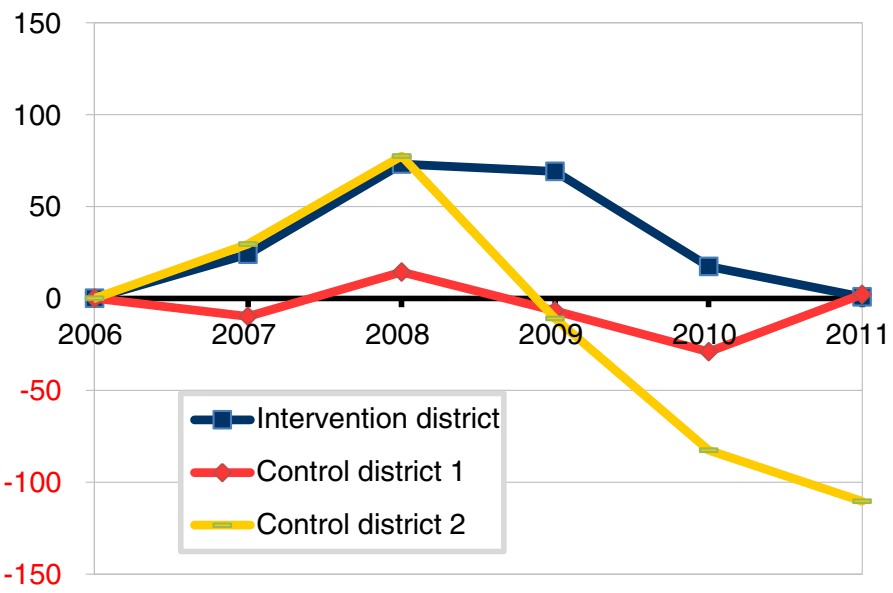

Fig. 2 Trend in actual versus expected weighted number units, for different types of GP care, 2006-2011 (index:2006), in intervention district and control districts. a Difference in actual versus expected number of regular GP consultations (2006 = index). b Difference in actual versus expected number of long GP consultations (2006 = index)

and education [29]. At the international level it voices the call for stronger primary care systems enabling a more generic comprehensive approach towards multimorbidity $[4,30]$.

In this perspective, our study findings supports the further exploration of this comprehensive integrated primary care, linking it up to the debates on reconfiguring health professionalism [21], on the modernising of education and new professional expertise [31], on the self-management by patients [32], on integrating public health and primary care [5, 15-18], and on applying complex adaptive systems thinking within primary care [33, 34].

Above all, the key contribution of our study lies in the dynamics in health care use found. Our study suggests that substituting GP care for hospital care is possible. Many health policies across countries aim to achieve this substitution, while supporting evidence is limited [35, 36].

It further may shed some light on the way more comprehensive primary care could absorb hospital use. Our study shows that GP's do spend more time on patients with an accumulation of problems, resulting in an increase in the number of regular $10 \mathrm{~min}$ and longer consultations. This goes along with GP's seeing more patients during out-of-office hours, which may reflect an improved accessibility and continuity of GP care, potentially reducing unnecessary Emergency Room visits as well. This result is in accordance with the findings of a recent international survey in 34 countries [37]. 
Table 4 Actual and expected use of different types of hospital care, in intervention district and control districts, 2006-2011

\begin{tabular}{|c|c|c|c|c|c|c|c|c|c|}
\hline \multirow{2}{*}{ Year } & \multicolumn{3}{|c|}{ Intervention district } & \multicolumn{3}{|c|}{ Control district 1} & \multicolumn{3}{|c|}{ Control district 2} \\
\hline & $\begin{array}{l}\text { Number } \\
\text { actual per } \\
1000\end{array}$ & $\begin{array}{l}\text { Number } \\
\text { expected per } \\
1000\end{array}$ & $\begin{array}{l}\text { Difference } \\
\text { actual and } \\
\text { expected }\end{array}$ & $\begin{array}{l}\text { Number } \\
\text { actual per } \\
1000\end{array}$ & $\begin{array}{l}\text { Number } \\
\text { expected per } \\
1000\end{array}$ & $\begin{array}{l}\text { Difference } \\
\text { actual and } \\
\text { expected }\end{array}$ & $\begin{array}{l}\text { Number } \\
\text { actual per } \\
1000\end{array}$ & $\begin{array}{l}\text { Number } \\
\text { expected per } \\
1000\end{array}$ & $\begin{array}{l}\text { Difference } \\
\text { actual and } \\
\text { expected }\end{array}$ \\
\hline \multicolumn{10}{|c|}{ Ambulatory care } \\
\hline 2006 & 940 & 952 & -12 & 927 & 935 & -8 & 960 & 892 & 68 \\
\hline 2007 & 930 & 960 & -30 & 937 & 949 & -12 & 962 & 903 & 58 \\
\hline 2008 & 805 & 872 & -67 & 831 & 874 & -42 & 845 & 830 & 15 \\
\hline 2009 & 802 & 883 & -81 & 847 & 894 & -48 & 878 & 842 & 36 \\
\hline 2010 & 863 & 911 & -48 & 914 & 925 & -12 & 918 & 859 & 59 \\
\hline 2011 & 913 & 951 & -38 & 972 & 959 & 13 & 971 & 898 & 73 \\
\hline \multicolumn{10}{|c|}{ Clinical care } \\
\hline 2006 & 143 & 132 & 11 & 137 & 131 & 7 & 132 & 121 & 11 \\
\hline 2007 & 138 & 132 & 7 & 135 & 133 & 2 & 133 & 126 & 7 \\
\hline 2008 & 140 & 140 & 0 & 140 & 138 & 3 & 132 & 132 & -0 \\
\hline 2009 & 154 & 161 & -6 & 159 & 164 & -5 & 151 & 154 & -3 \\
\hline 2010 & 160 & 171 & -11 & 171 & 174 & -2 & 153 & 159 & -6 \\
\hline 2011 & 161 & 173 & -12 & 170 & 177 & -7 & 160 & 167 & -7 \\
\hline \multicolumn{10}{|c|}{ 1-day Hospitalizations } \\
\hline 2006 & 80 & 67 & 13 & 78 & 69 & 9 & 69 & 63 & 6 \\
\hline 2007 & 88 & 72 & 16 & 88 & 77 & 11 & 76 & 68 & 8 \\
\hline 2008 & 82 & 76 & 6 & 93 & 83 & 10 & 81 & 73 & 9 \\
\hline 2009 & 98 & 85 & 13 & 106 & 95 & 11 & 93 & 82 & 12 \\
\hline 2010 & 100 & 94 & 6 & 121 & 104 & 17 & 100 & 90 & 10 \\
\hline 2011 & 105 & 101 & 5 & 123 & 113 & 10 & 103 & 97 & 6 \\
\hline
\end{tabular}

\section{Difference in actual versus expected ambulatory hospital care (2006=index)}

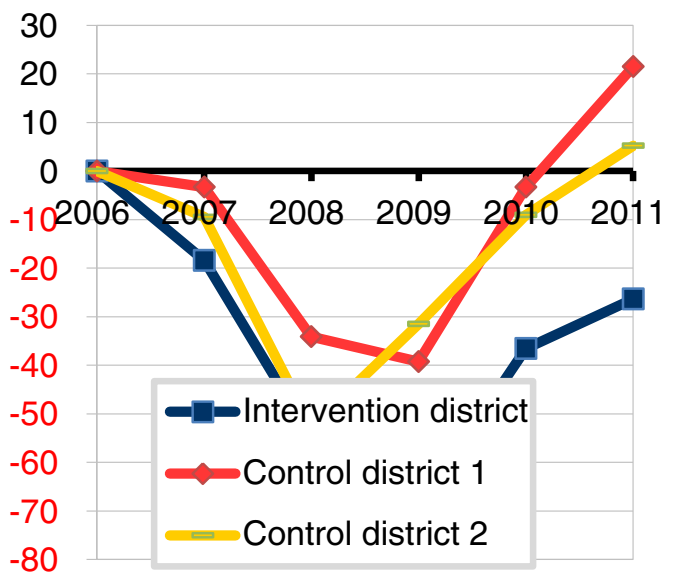

Fig. 3 Trend in actual versus expected weighted number units, for ambulatory hospital care, 2006-2011 (index:2006), in intervention district and control districts. Difference in actual versus expected ambulatory hospital care $(2006=$ index $)$
In addition to the above mentioned explanations related to the behaviour of the provider, the impact on health care use might also be the result of changing health behaviour of patients. Unfortunately, no data are available to further examine this factor. It is recommended that future research tries to disentangle the effects of the interventions directed at providers and at patients.

\section{Strengths and limitations of this study}

Our study provides a unique exploration of the potential impact a comprehensive integrated care approach could have on health care use for people in deprived districts. Its strength lies in the large number of respondents included in the study and the two control districts. Moreover, the Agis Health Insurance sample included almost $2 / 3$ of the residents in Overvecht. In previous studies, this population has been proven to be representative for the total Dutch urban population [26], limiting the risk of selection bias. Given the gradual uptake of the integrated care approach from 2006 and onwards [25], we could only warrant the comparability of data by including data from 2006 to 2011 for which it was also likely that an 
increasing impact in health care use would have occurred. Before 2006 and from 2012 onwards, data were incomparable as the financing system of healthcare in The Netherlands changed. Ideally, we would have included utilization data for other primary care providers, medication use, and social care providers, but this was not possible for reasons of data comparability, availability and complexities such as the introduction of new professionals over time. We therefore recommend further research in studying the impact on other primary care services, public health, and social care services.

The somewhat similar direction of trends in the intervention district and control district 1 (although they differed in their intensity of change) may point to spill over effects potentially caused by the media attention for the intervention. If this is the case, this means our findings in the intervention district are an underestimation of the actual impact of the integrated care approach on health care use.

Finally, we have checked the stability in composition of insured clients over time, and only noticed small changes. We do not expect this to have influenced the changes in health care utilization we found because we used standardized utilization data, and because the differences between districts remain constant over time.

\section{Conclusions}

Utilization patterns for general practice and hospital care of people living in deprived districts may change when primary care professionals work in a more coherent and coordinated manner by applying a more 'comprehensive' integrated care approach. Results supports the further exploration of the potential of 'comprehensive' integrated care embedded in primary care in deprived neighbourhoods to the future sustainability of healthcare systems.

\section{Additional file}

Additional file 1: Table S1. Activities implemented in Utrecht Overvecht to promote renewal of expertise from 2006-2011. (DOCX $19 \mathrm{~kb}$ )

\footnotetext{
Acknowledgements

The authors are grateful to the contributions made by Judith van de Mast, Mascha Egberts and Anne Hollinga from Agis Health Insurance/Achmea Care and Health (currently known as 'Zilveren Kruis') throughout the course of this study.
}

\section{Funding}

This study was funded by the Netherlands Organisation for Health Research and Development (ZonMW), Preventieprogramma 4, Grant No. 200320005. ZonMW had no role in the execution of the study or the preparation of the manuscript.

\section{Availability of data and material}

Aggregated data is shared in Tables 2, 3 and 4. Individual level data will not be shared, because it concerns health care consumption data from a private health insurance company.

\section{Authors' contributions}

DK conducted the study, performed the data analyses and drafted the manuscript. JvdB contributed to writing the manuscript and provided feedback on all drafts of the manuscript. AvdL collected the data, prepared the data analysis plan, supported the interpretation of results and commented on drafts of the manuscript. TP and KS designed the study, and provided advice on all stages of the study, and contributed to drafting the manuscript. All authors read and approved the final manuscript.

\section{Competing interests}

The authors declare that they have no competing interests.

\section{Consent for publication}

Not applicable.

Ethics approval and consent to participate

Not required.

The authors received permission from Agis Health Insurance to use data from the Agis Health Database.

\section{Author details}

${ }^{1}$ Department of Public Health, Academic Medical Center (AMC), University of Amsterdam, PO-box 22660, Amsterdam 1100 DD, The Netherlands.

${ }^{2}$ Kenniscentrum, Zilveren Kruis Achmea, Storkstraat 12, Leusden 3833 LB, The Netherlands.

Received: 7 August 2015 Accepted: 29 June 2016

Published online: 11 July 2016

\section{References}

1. Pickett KE, Pearl M. Multilevel analyses of neighbourhood socioeconomic context and health outcomes: a critical review. J Epidemiol Community Health. 2001;55:111-22.

2. Riva M, Gauvin L, Barnett TA. Toward the next generation of research into small area effects on health: a synthesis of multilevel investigations published since July 1998. J Epidemiol Community. 2007:61:853-61.

3. Ellaway A, Benzeval M, Green M, Leyland A, Macintyre S. "Getting sicker quicker": Does living in a more deprived neighbourhood mean your health deteriorates faster? Health Place. 2012;18:132-7.

4. Barnett K, Mercer SW, Norbury M, Watt G, Wyke S, Guthrie B. Epidemiology of multimorbidity and implications for health care, research, and medical education: a cross-sectional study. Lancet. 2012;380(9836):37-43.

5. Martin-Misener R, Valaitis R, Wong ST, Macdonald M, Meagher-Stewart D, Kaczorowski J, et al. A scoping literature review of collaboration between primary care and public health. Prim Health Care Res Dev. 2012;13(4):327-46.

6. Bhopal R. Medicine and public health in a multiethnic world. J Pub Health. 2009;31(3):315-21.

7. Commission on Social Determinants of Health. Closing the gap in a generation: health equity through action on the social determinants of health. Final Report of the Commission on Social Determinants of Health. Geneva: World Health Organization; 2008.

8. Mackenbach JP, Stronks K. A strategy for tackling health inequalities in the Netherlands. BMJ. 2002;325(7371):1029-32.

9. Stronks K, Ravelli AC, Reijneveld SA. Immigrants in the Netherlands: equal access for equal needs? J Epidemiol Community Health. 2001;55(10):701-7.

10. OECD. Health Reform, meeting the challenges of ageing and multiple morbidities. Paris: OECD; 2011.

11. Glynn LG, Valderas JM, Healy P, Burke E, Newell J, Gillespie P, et al. The prevalence of multimorbidity in primary care and its effect on health care utilization and cost. Fam Pract. 2011;28(5):516-23.

12. Robert Wood Johnson Foundation. Chronic Care: Making the Case for Ongoing Care. New Jersey: Robert Wood Johnson Foundation; 2010.

13. Singer SJ, Burgers J, Friedberg M, Rosenthal MB, Leape L, Schneider E. Defining and measuring integrated patient care: promoting the next frontier in health care delivery. Med Care Res Rev. 2011;68(1):112-27. 
14. Kodner DL, Spreeuwenberg C. Integrated care: meaning, logic, applications, and implications-a discussion paper. Int J Integr Care. 2002;2:e12.

15. Plochg T. Building a tower of Babel in health care? Theory \& practice of community based integrated care. Amsterdam: University of Amsterdam; 2006

16. Stevenson Rowan M, Hogg W, Huston P. Integrating public health and primary care. Healthcare Pol. 2007;3(1):e160-181.

17. Valentijn PP, Vrijhoef HJM, Ruwaard D, Boesveld I, Arends RY, Bruijnzeels MA Towards an international taxonomy of integrated primary care: a Delphi consensus approach. BMC Fam Pract. 2015;16:64.

18. Scutchfield FD, Michener JL, Thacker SB. Are we there yet? Seizing the moment to integrate medicine and public health. Am J Public Health. 2012; 102 Suppl 3:S312-316.

19. Koo D, Felix K, Dankwa-Mullan I, Miller T, Waalen J. A call for action on primary care and public health integration. Am J Pub Health. 2012;102 Suppl 3:S307-309.

20. Nolte E, McKee M. Integration and chronic care: a review. In: Nolte E, McKee M, editors. Caring for People with Chronic Conditions A Health System Perspective. London: European Observatory on Health Systems and Policies Series; 2008. p. 64-91.

21. Plochg T, Klazinga NS, Starfield B. Transforming medical professionalism to fit changing health needs. BMC Med. 2009;7:64.

22. Starfield B. Point: the changing nature of disease: implications for health services. Med Care. 2011;49(11):971-2.

23. Doessing A, Burau V. Care coordination of multimorbidity: a scoping study. J Comorbidity. 2015;5(1):15-28.

24. Salisbury C, Johnson L, Purdy S, Valderas JM, Montgomery AA Epidemiology and impact of multimorbidity in primary care: a retrospective cohort study. Br J Gen Pract. 2011;61(582):e12-21.

25. van den Broeke J, van der Aa M, Busschers W, Stronks K, Plochg T. Renewing the expertise of health and social care professionals to provide integrated care: Evaluation of an intervention in a deprived Dutch neighbourhood. Eur J Person Centered Healthcare. 2015;3(4):442-53.

26. Smeets HM, de Wit NJ, Hoes AW. Routine health insurance data for scientific research: potential and limitations of the Agis Health Database. J Clin Epidem. 2011;64(4):424-30.

27. Struijs JN, Drewes HW, Heijink R, Baan CA. How to evaluate population management? Transforming the Care Continuum Alliance population health guide toward a broadly applicable analytical framework. Health Policy. 2015; 119:522-9.

28. Council for Public Health and Health Care. Perspective on Health 20/20. Report by the Council for Public Health and Health Care to the Minister of Health, Welfare and Sport. The Hague: Koninklijke Broese \& Peereboom; 2010

29. Kaljouw M, van Vliet K. Towards new healthcare and healthcare professions: the contours. White paper of the Committee on Innovating Healthcare Professions and Education. Diemen: National Healthcare Institute; 2010 [In Dutch].

30. De Maeseneer J, Boeckxtaens P. James Mackenzie Lecture 2011 multimorbidity, goal-oriented care, and equity. Br J Gen Pract. 2012;62(600): e522-e523.

31. Kendrick T. 30th George Swift Lecture: generalism in undergraduate medical education - what's next? Br J Gen Pract. 2012;62(599):323-5.

32. Thompson AG. The meaning of patient involvement and participation in health care consultations: A taxonomy. Soc Sci Med. 2007;64:1297-310.

33. Sturmberg JP. Primary health care organizations - through a conceptual and a political lens. J Eval Clin Pract. 2011;17:525-9.

34. Reeve J, Blakeman T, Freeman GK, Green LA, James PA, Lucassen P, Martin CM, Sturmberg JP, van Weel C. Generalist solutions to complex problems: generating practice-based evidence - the example of managing multimorbidity. BMC Fam Pract. 2013;14:112.

35. Rosano A, Loha CA, Falvo R, van der Zee J, Ricciardi W, Guasticchi G, et al. The relationship between avoidable hospitalization and accessibility to primary care: a systematic review. Eur J Pub Health. 2013;23(3):356-60.

36. van Loenen T, van den Berg MJ, Westert GP, Faber MJ. Organizational aspects of primary care related to avoidable hospitalization: a systematic review. Fam Pract. 2014;31(5):502-16.
37. van den Berg MJ, van Loenen T, Westert GP. Accessible and continuous primary care may help reduce rates of emergency department use. An international survey in 34 countries. Fam Pract. 2016;33(1):42-50.

38. Utrecht Buurtmonitor [http://utrecht.buurtmonitor.nl/]. Accessed 13 Oct 2014.

39. Raedelijn [http://raedelijn.rosopen.databank.nl/]. Accessed 13 Oct 2014.

\section{Submit your next manuscript to BioMed Central and we will help you at every step:}

- We accept pre-submission inquiries

- Our selector tool helps you to find the most relevant journal

- We provide round the clock customer support

- Convenient online submission

- Thorough peer review

- Inclusion in PubMed and all major indexing services

- Maximum visibility for your research

Submit your manuscript at www.biomedcentral.com/submit 